\title{
Thermal-Hydraulic Performance of Graphene Nanoribbon and Silicon Carbide Nanoparticles in the Multi-Louvered Radiator for Cooling Diesel Engine
}

\author{
Nogueira E.
}

Department of Mechanics and Energy, State University of Rio de Janeiro, Brazil

\section{Article info:}

Paper received:

The final version of the paper received:

Paper accepted online:
January 24,2020

May 3, 2020

May 17, 2020
*Corresponding email:

elcionogueira@hotmail.com

\begin{abstract}
Analytical solution for application and comparison of Graphene Nanoribbon and Silicon Carbide for thermal and hydraulic performance in flat tube Multi-Louvered Finned Radiator is presented. The base fluid is composed of pure water and ethylene glycol at a 50\% volume fraction. The results were obtained for Nusselt number, convection heat transfer coefficient and pressure drop, for airflow in the radiator core and nanofluids in flat tubes. The main thermal and hydraulic parameters used are the Reynolds number, the mass flow rate, the Colburn Factor, and Friction Factor. In some situations, under analysis, the volume fraction, for Graphene Nanoribbon and Silicon Carbide, were varied. The value of the heat transfer coefficient obtained for Graphene Nanoribbon, for the volume fraction equal 0.05 , is higher than twice the amount received by Silicon Carbide. The flow is laminar, for whatever the fraction value by volume of the Graphene nanoparticles when the mass flow of the nanofluid is relatively low. For turbulent flow and relatively small fractions of nanoparticles, the heat transfer coefficient is significantly high for mass flow rates of Graphene Nanoribbon. The pressure drop, for the same volume fraction of nanoparticles, is slightly higher than the pressure drop associated with Silicon Carbide. These high values for the heat transfer coefficient is a favorable result and of great practical importance, since lower values for the fraction in volume can reduce the costs of the compact heat exchanger (radiator).
\end{abstract}

Keywords: analytical solution, nanofluid, compact exchanger, automotive radiator.

\section{Introduction}

The water is still the best refrigerant, but it is corrosive and contains dissolved salts that degrade the coolant. Eventually, every automotive cooling system will erode, and some additive will increase the life of the cooling system. An additive mixture, like Ethylene Glycol, for automobile radiator is meant to reduce cooling system corrosion and raise the boiling point of the base fluid. The mix of water and Ethylene Glycol is to be as effective of pure water, and for this, its mass flow rate or volume fraction should be increased [1].

Ethylene Glycol (EG) is an antifreeze used, because of its compatibility with metals, in automobile radiators for many years. The mixture of Ethylene Glycol and water is mostly used in automotive vehicles, but the low thermal conductivity of the base fluids is a concern.

Ethylene Glycol in its pure form, it is odorless, and ingestion can result in death.
The high thermal conductivity of solids is to increase the thermal conductivity of a fluid by adding nanoparticles [2].

Nanofluids have aroused great interest due to their thermo-physical properties and numerous potential benefits for the field of research in multiple areas [3].

Nanofluids consist of suspended nanoparticles with average sizes below $100 \mathrm{~nm}$ in fluids, such as a mixture of water and ethylene glycol. Suspended nanoparticles can alter the mass and energy transport properties of the base fluid [4].

\section{Literature Review}

High thermal effectiveness is highly desirable for heat transfer applications. The nanofluid has the heat transfer superior to the respective base-fluid that has been usually used in an automotive vehicle. There are many obstacles to the use of nanoparticles to be overcome. The production cost is very high, and the specific heat decreases with the 
increase in the volume fraction, which makes them less suitable for use in refrigeration systems [5].

Graphene nanoribbon is a two-dimensional monolayer of carbon atoms that possesses remarkable thermal properties and has a large surface area. It makes graphene nanoribbon an attractive candidate for biomedical applications, conductive textile coatings, optical elements, battery electrode materials, and automotive radiators [6].

Zadeh S. J. M.; Goharshadi E. K. [7] investigated the thermal conductivity of graphene nanofibers, and the results obtained indicated high thermal conductivities. The results obtained experimentally, depending on the size of the nanoparticles, showed that the thermal conductivity reaches a minimum value of $1500 \mathrm{~W} /(\mathrm{m} \mathrm{K})$. However, they show that results obtained for graphene nanoribbons indicate that the thermal conductivity can reach $5000 \mathrm{~W} /(\mathrm{m} \mathrm{K})$ and that it has a lower density than metal nanoparticles and metal oxide.

Silicon carbide is a material that has found applications in a variety of industries. Forms of this material are in abrasive materials, and the more recent use is in semiconductors for high-temperature electronic devices [8].

An overview of the most common methods used for the elaboration of Silicon Carbide, as well as the mechanical, structural, and electrical properties, were presented by Abderrazak H., and Hmida E. S. [9].

Silicon carbide has advantages for use in specialized applications, as it has excellent thermal properties, especially in applications in high temperature and highpower devices [10].

Silicon carbide is usually used as a full bandgap semiconductor and exhibits a high thermal conductivity. The mechanicals and thermal qualities make Silicon carbide a perfect candidate for applications at high temperatures as well as abrasion and cutting applications [9].

The thermal conductivity of Silicon-Graphene nanoribbon is investigated and compared to that of graphene nanoribbon and silicene nanoribbon [11].

Nanotechnology is rapidly developing, and its use is found in most areas of engineering. Compared to conventional solid-liquid, nanofluids show better results. Due to its high thermal performance, the potential in specific industrial applications has increased over the years [12].

Selvam C. et al. [12] report graphene seeded in waterethylene glycol mixture flowing through an automobile radiator, and thermophysical properties were measured experimentally.

Extended surfaces have been developed to reduce the size and weight of heat exchangers, and the fin geometries are plain fins, wavy fins, offset fins, perforated fins, pin fins, and louvered fins. Multi-Louvered fin and flat tubes have a higher degree of surface compactness due to the periodic starting and development of the laminar boundary layer over the interrupted channels formed by the louvered fins.

Dong J. et al. [13] performed experimental studies on the airside heat transfer and pressure drop characteristics for 20 types of Multi-Louvered fin and flat tube heat exchangers. They showed a series of tests that were conducted for air Reynolds numbers of 200-2 500 based on the louver pitch with different fin pitch, fin height, fin thickness, fin louver angle, and flow length at a constant tube side flow rate of $2.8 \mathrm{~m}^{3} / \mathrm{h}$. Characteristics of the heat transfer and pressure drop for the different geometry parameters were reported in terms of the Colburn $\mathrm{j}$-factor and Fanning friction $\mathrm{f}$-factor as a function of $R e_{L p}$.

Sarkar J. and Tarodiya R. [14] have performed the louvered fin tube automotive radiator using nanofluids as coolants. They reveal that the nanofluids may effectively use as the coolant in automotive radiators to improve the performance.

\section{Research Methodology}

Figure 1 shows some geometric parameters of the Multi-Louvered fin heat exchanger.

Figure 2 shows the details of its construction, Crosssection of Multi-Louvered fin geometry. These parameters are essential to obtain the Colburn Factor and Friction Factor.

Dong J. et al. [13] received the correlations of the $j$, Colburn factor, and $f$, friction factor using from 20 MultiLouvered fins and flat tube heat exchangers, according to Table 1.

In this work, we used, for numerical and graphic determination of the physical quantities of interest, the geometric characteristics presented in Table 1, and thermal physical properties - in Table 3.
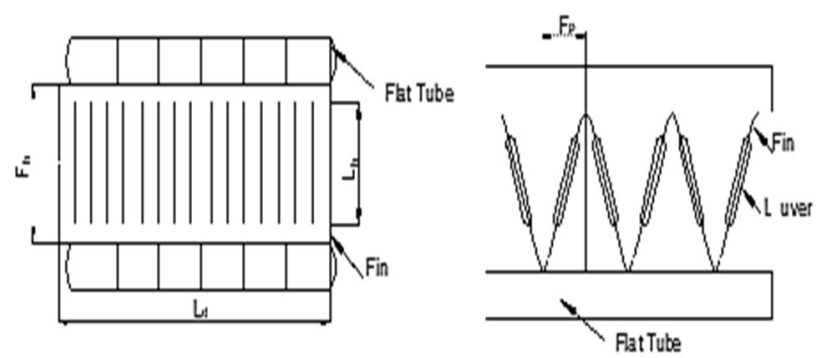

Figure 1 - Geometrical parameters for a Multi-Louvered fin heat exchanger (Sarkar J. and Tarodiya R. [14])

Table 2 presents the geometry characteristics of the Flat Tube Multi-Louvered Radiator Compact Heat Exchanger, presented by Sarkar J. and Tarodiya R. [14].

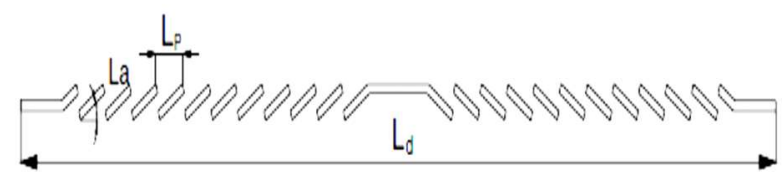

Figure 2 - Cross-section of Multi-Louvered fin geometry (Sarkar J. and Tarodiya R. [14])

The radiator is mounted on a turbocharged diesel engine. It consists of 644 tubes manufactured in brass and 346 continuous fins in aluminum alloy whose thermal conductivity is $177 \mathrm{~W} /(\mathrm{m} \mathrm{K})$. 
The numerical correlations used for determination of $j$ factor and $f$ factor are:

$$
\begin{aligned}
\mathrm{j}_{\mathrm{Lp}}= & 0.2712 R e_{L p}-0.1944\left(\frac{L_{a}}{90}\right)^{0.257}\left(\frac{F_{p}}{L_{p}}\right)^{-0.5177} ; \\
& \left(\frac{F_{h}}{L_{p}}\right)^{-1.9045}\left(\frac{L_{h}}{L_{p}}\right)^{1.7159}\left(\frac{L_{d}}{L_{p}}\right)^{-0.2147}\left(\frac{\delta}{L_{p}}\right)^{-0.05 ;} \\
f_{L p}= & 0.54486 R e_{L p}^{-0.3068}\left(\frac{L_{a}}{90}\right)^{0.444}\left(\frac{F_{p}}{L_{p}}\right)^{-0.9925} ; \\
& \left(\frac{F_{h}}{L_{p}}\right)^{0.5458}\left(\frac{L_{h}}{L_{p}}\right)^{-0.2003}\left(\frac{L_{d}}{L_{p}}\right)^{0.0688} ;
\end{aligned}
$$

and

$$
R e_{L p}=\frac{u L_{p}}{\vartheta}
$$

\begin{tabular}{|c|c|c|c|c|c|}
\hline$F_{p}$ & $F_{h}$ & $L_{d}$ & $\delta$ & $L_{n},{ }^{\circ}$ & $L_{p}$ \\
\hline 2.00 & \multirow{6}{*}{8.0} & \multirow{3}{*}{65.0} & \multirow{11}{*}{0.20} & \multirow{11}{*}{28} & \multirow{20}{*}{1.2} \\
\hline 2.25 & & & & & \\
\hline 2.50 & & & & & \\
\hline 2.00 & & \multirow{3}{*}{53.0} & & & \\
\hline 2.25 & & & & & \\
\hline 2.50 & & & & & \\
\hline 2.00 & \multirow{3}{*}{7.0} & \multirow{5}{*}{36.6} & & & \\
\hline 2.25 & & & & & \\
\hline 2.50 & & & & & \\
\hline 2.00 & 10.0 & & & & \\
\hline 2.00 & 8.0 & & & & \\
\hline 2.00 & \multirow{9}{*}{8.9} & 65.0 & \multirow{9}{*}{0.15} & \multirow{9}{*}{22} & \\
\hline 2.00 & & 53.0 & & & \\
\hline 2.00 & & 36.6 & & & \\
\hline 2.25 & & & & & \\
\hline 2.50 & & 53.0 & & & \\
\hline 2.75 & & & & & \\
\hline 2.25 & & \multirow{3}{*}{65.0} & & & \\
\hline 2.5 & & & & & \\
\hline 2.75 & & & & & \\
\hline
\end{tabular}

where $u$ - air velocity among fins, $\mathrm{m} / \mathrm{s} ; \vartheta$ - kinematic viscosity $\mathrm{m}^{2} / \mathrm{s}$.

Table 1 - Specification of Multi-Louvered fin parameters, mm (Dong J. et al. [13])

Table 2 - Surface core geometry of flat tubes (Sarkar J. and Tarodiya R. [14])

\begin{tabular}{|l|c|c|}
\hline \multicolumn{1}{|c|}{ Description } & Air side & $\begin{array}{c}\text { Coolant } \\
\text { side }\end{array}$ \\
\hline Core width, $\mathrm{m}$ & \multicolumn{2}{|c|}{0.6} \\
\hline Core height, $\mathrm{m}$ & \multicolumn{2}{|c|}{0.5} \\
\hline Core depth, $\mathrm{m}$ & 446 & - \\
\hline Fin pitch, $\mathrm{m}^{-1}$ & 0.1 & - \\
\hline Fin metal thickness, $\mathrm{mm}$ & 35.1 & 37.3 \\
\hline Hydraulic diameter, $\mathrm{mm}$ & 0.780 & 0.129 \\
\hline $\begin{array}{l}\text { Min. free flow area } \\
\text { per front area }\end{array}$ & 886 & 138 \\
\hline $\begin{array}{l}\text { Total heat transfer } \\
\text { area, } \mathrm{m}^{2} / \mathrm{m}^{3}\end{array}$ & 0.845 & - \\
\hline Fin area per total area &
\end{tabular}

Table 3 presents the thermal physical properties of the base fluid of Water-EG $50 \%$, Air, Silicon Carbide, and Graphene Nanoribbon used in this work.

Table 3 - Thermal physical properties

\begin{tabular}{|l|c|c|c|c|}
\hline \multicolumn{1}{|c|}{ Properties } & Water & $\begin{array}{c}\text { Ethylene } \\
\text { Glycol } \\
\text { EG 50 \% }\end{array}$ & $\begin{array}{c}\text { Silicon } \\
\text { Carbide }\end{array}$ & $\begin{array}{c}\text { Graphene } \\
\text { Nano- } \\
\text { ribbon }\end{array}$ \\
\hline $\begin{array}{l}\text { Conductivity, } \\
\mathrm{W} /(\mathrm{m} \cdot \mathrm{K})\end{array}$ & 0.605 & 0.422 & 350 & 1250 \\
\hline $\begin{array}{l}\text { Density, } \\
\mathrm{kg} / \mathrm{m}^{3}\end{array}$ & 1000 & 1058 & 3160 & 995 \\
\hline $\begin{array}{l}\text { Specific heat, } \\
\mathrm{J} /(\mathrm{kg} \cdot \mathrm{K})\end{array}$ & 4184 & 3879 & 1340 & 4179 \\
\hline $\begin{array}{l}\text { Viscosity, } \\
10^{-4} \mathrm{~kg} /(\mathrm{m} \cdot \mathrm{s})\end{array}$ & 4.75 & 9.81 & - & - \\
\hline $\begin{array}{l}\text { Viscosity, } \\
10^{-6} \mathrm{~m} / \mathrm{s}\end{array}$ & 1.00 & 0.93 & - & - \\
\hline $\begin{array}{l}\text { Dissusivity, } \\
10^{-6} \mathrm{~m}^{2} / \mathrm{s}\end{array}$ & 0.144 & 0.103 & 82.66 & 3008 \\
\hline
\end{tabular}

The correlations for Colbourn Factor and Friction Factor, for parameters used in this work, are represented in Figures 3 and 4.

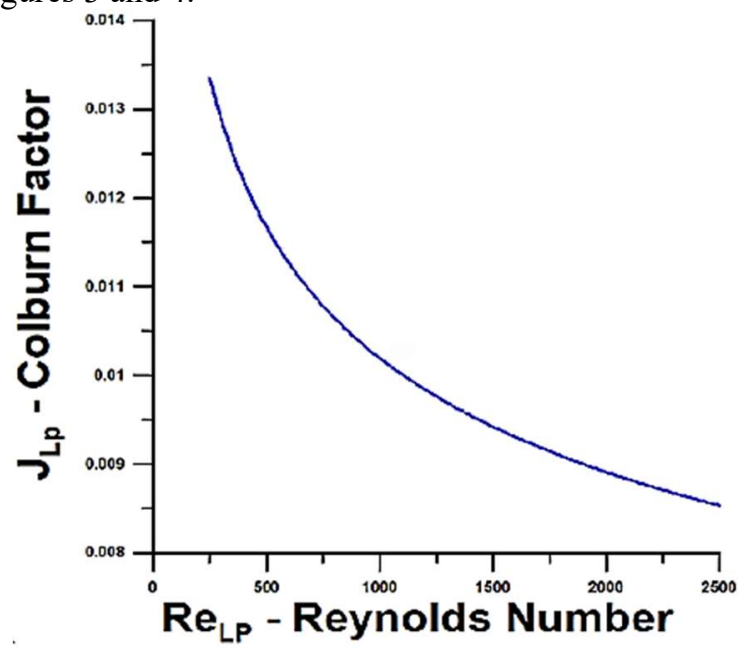

Figure 3 - Colburn Factor for the data in Table 1 (column 11)

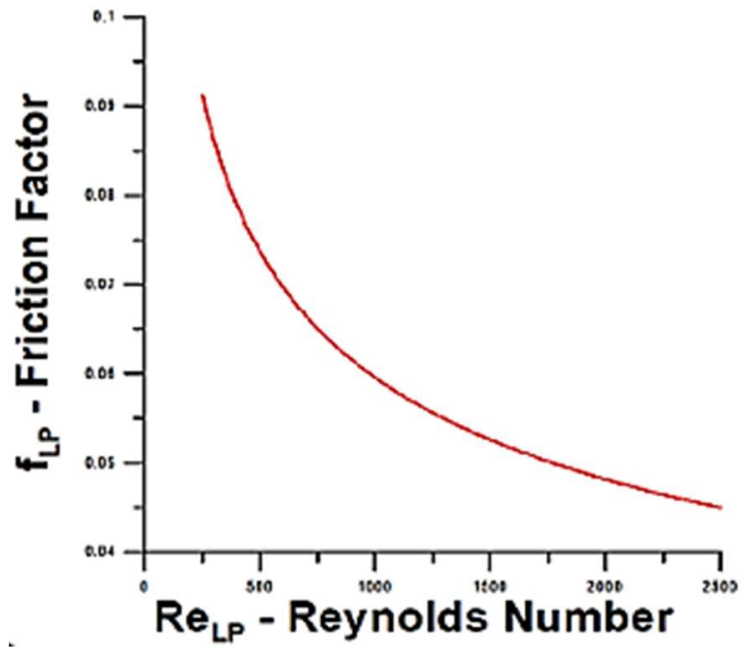

Figure 4 - Friction Factor for the data in Table 1 (column 11) 
The properties of the ethylene-based aqueous solution are obtained by the expressions below:

$$
\begin{aligned}
& \rho_{\text {solution }}=\rho_{\mathrm{EG} \%} \mathrm{~V}+(1-\mathrm{V}) \rho_{\mathrm{w}} \\
& \mu_{\text {solution }}=\mu_{\mathrm{EG} \%} \mathrm{~V}+(1-\mathrm{V}) \mu_{\mathrm{W}} \\
& \mathrm{C}_{\text {solution }}=\mathrm{C} \mathrm{p}_{\mathrm{EG} \%} \mathrm{~V}+(1-\mathrm{V}) \mathrm{C} \mathrm{p}_{\mathrm{w}} \\
& \mathrm{k}_{\text {solution }}=\mathrm{k}_{\mathrm{EG} \%} \mathrm{~V}+(1-\mathrm{V}) \mathrm{K}_{\mathrm{w}} \\
& \alpha_{\text {solution }}=\frac{\mathrm{k}_{\text {solution }}}{\rho_{\text {solution }} \mathrm{Cp}} \mathrm{p}_{\text {solution }} \\
& \vartheta_{\text {solution }}=\frac{\mu_{\text {solution }}}{\rho_{\text {solution }}} \\
& \operatorname{Pr}_{\text {solution }}=\frac{\alpha_{\text {solution }}}{\vartheta_{\text {solution }}}
\end{aligned}
$$

where $\mathrm{V}$ and $\mathrm{Eg} \%$ are the volume fraction percent of water and weight fraction percent of Ethylene Glycol, respectively.

For water ethylene-based nanofluid properties we have:

$$
\begin{aligned}
& \rho_{\text {nano }}=\emptyset \rho_{\text {particle }}+(1-\emptyset) \rho_{\text {solution }} ; \\
& \mu_{\text {nano }}=\mu_{\text {solution }}\left(1-0.19 \emptyset+306 \emptyset^{2}\right) ; \\
& C p_{\text {nano }}=\left(\varnothing \rho_{\text {particle }} C p_{\text {particle }}+\right. \\
& \left.(1-\emptyset) \rho_{\text {solution }} C p_{\text {solution }}\right) / \rho_{\text {nano }} ; \\
& k_{\text {nano }}=\left[\left(k_{\text {particle }}+2 k_{\text {solution }}+2\left(k_{\text {partion }}\right)(1-0.1)^{3}\right.\right. \\
& +2 k_{\text {solution }}\left(k_{\text {particle }}\right. \\
& \left.\left.\left.-k_{\text {solution }}\right)(1+0.1)^{2} \emptyset\right)\right] k_{\text {solution }} ; \\
& \alpha_{\text {nano }}=\frac{k_{\text {nano }}}{\rho_{\text {nano }} C p_{\text {nano }}} ; \\
& \vartheta_{\text {nano }}=\frac{\rho_{\text {nano }}}{\mu_{\text {nano }}} ; \\
& \operatorname{Pr}_{\text {nano }}=\frac{\alpha_{\text {nano }}}{\vartheta_{\text {nano }}}
\end{aligned}
$$$$
k_{\text {nano }}=\left[\left(k_{\text {particle }}+2 k_{\text {solution }}+2\left(k_{\text {particle }}\right.\right.\right.
$$$$
\left.\left.-k_{\text {solution }}\right)(1-0.1)^{3} \emptyset\right) /\left(k_{\text {particle }}+\right.
$$

at where $\varnothing$ is the volume fraction of nanoparticles.

Equation (12) is the correlation obtained by Maiga et al. [15]. Other quantities associated with the flow are achieved by:

$$
R \mathrm{e}_{\text {nano }}=\frac{4\left(\frac{m_{\text {nano }}}{N_{\text {tubes }}}\right)}{\pi D_{\text {hnano }} \mu_{\text {nano }}}
$$

at where

$$
D_{\text {hnano }}=3.7310^{-3} \text {. }
$$

Considering the flow regime of the Newtonian flow of a water-base nanofluid in the tube as completely developed, we have, for turbulent flow, approximately:

$N u_{\text {nano }}=0,021 R e_{\text {nano }}{ }^{0,8} \operatorname{Pr}_{\text {nano }}{ }^{0,5}$.

Correlation expressed by Pak B. C. and Cho Y. I. [16]: $N u_{\text {nano }}=1.953\left(\operatorname{Re}_{\text {Dhnano }} P r_{\text {nano }} \frac{D_{\text {hna }}}{L_{\text {tube }}}\right)^{1 / 3}$;

$R e_{\text {Dhnan }} \operatorname{Pr}_{\text {nano }} \frac{D_{\text {hnano }}}{L_{\text {tube }}} \geq 33.3$

Correlation expressed by Hussein A. M. et al. [17]:

$N u_{\text {nano }}=0.012\left(\operatorname{Re}_{\text {nano }}^{0.87}-280\right) P r_{\text {nano }}^{0.4}\left[1+\left(\frac{D_{\text {hnano }}}{L_{\text {tube }}}\right)^{2 / 3}\right]$.

According to the correlation expressed by Gnielinski V. [18], if the flow regime in the water-base nanofluid is laminar, for the thermal input region under development:

$$
\begin{aligned}
& N u_{\text {nano }}=1.409019812 d 0 Z_{\text {nano }}{ }^{-0.351} \text {; } \\
& 10^{-5} \leq Z_{\text {nano }}<10^{-3} \text {; } \\
& N u_{\text {nano }}=1.519{\mathrm{~d} 0 Z_{\text {nano }}}^{-0.340} \text {; } \\
& 10^{-3} \leq Z_{\text {nano }}<10^{-2} \text {; } \\
& N u_{\text {nano }}=10.866-570.47 Z_{\text {nano }}+ \\
& +28981.7 Z_{\text {nano }}{ }^{2}-950934.0 Z_{\text {nano }}{ }^{3}+ \\
& +20237498.4 Z_{\text {nano }}^{4}-276705269.6 Z_{\text {nano }}{ }^{5}+ \\
& +2340349265 Z_{\text {nano }}{ }^{6}-1.112 \cdot 10^{10} Z_{\text {nano }}{ }^{7}+ \\
& +2.269345238^{10} Z_{\text {nano }}{ }^{8} \text {; } \\
& 10^{-2} \leq Z_{\text {nano }} \leq 10^{-1} \text {; } \\
& N u_{\text {nano }}=5.261 d 0-19.93 Z_{\text {nano }}+ \\
& +139.49 Z_{\text {nano }}{ }^{2}-606 Z_{\text {nano }}{ }^{3}+ \\
& +1716.1 Z_{\text {nano }}^{4}-3218 Z_{\text {nano }}{ }^{5}+ \\
& +3954.86 Z_{\text {nano }}{ }^{6}-3056.1 Z_{\text {nano }}{ }^{7}+ \\
& +1344.25 Z_{\text {nano }}{ }^{8}-256.283 Z_{\text {nano }}{ }^{9} \text {; } \\
& 10^{-1} \leq Z_{w} \leq 10^{0} \\
& \text { or }
\end{aligned}
$$

Then we have:

$h_{\text {nano }}=N u_{\text {nano }} \frac{k_{\text {nano }}}{D_{\text {hnano }}}$.

The friction factor and pressure drop for nanofluid are given by:

$$
f_{\text {nano }}=\frac{64}{\text { Re }_{\text {nano }}} ; R e_{\text {nano }} \leq 2100
$$

or 


$$
\begin{aligned}
& f_{\text {nano }}=\left[0.79 \operatorname{Ln}\left(R e_{\text {nano }}\right)-1.69\right]^{-2} ; \\
& R e_{\text {nano }}>2100 \text {; } \\
& \Delta P_{\text {nano }}=\frac{8 f_{\text {nano }} L_{\text {tube }} Q_{\text {nano }}{ }^{2}}{D h_{\text {nano }}{ }^{5} \pi^{2}} \rho_{\text {nano }} .
\end{aligned}
$$

\section{Results and discussion}

\subsection{Results for the airside}

Through Figures 5, 6, we present the values obtained for the heat transfer coefficient and the Nusselt number, concerning the heat exchanger core, that is, in the region where the airflow occurs. The equations used for these cases are:

$$
\begin{aligned}
& h_{a i r}=j_{L p} G_{a} C p_{a} / P r_{a}^{\frac{2}{3}} ; \\
& G_{a}=\frac{R e_{a} \mu_{a}}{D h_{a}} ; \\
& R e_{a}=\frac{D h_{a} R e_{L p}}{L_{p}} ; \\
& N u_{a}=\frac{D h_{a} h_{a i r}}{K_{a}} .
\end{aligned}
$$

Figure 7 present the pressure drop in the heat exchanger core (air), at where:

$$
\Delta P=\left(\frac{A_{O} f_{L p}}{A_{C}}+K_{c}+K_{e}\right) \frac{\rho_{a}}{2}\left(\frac{\vartheta_{a} R e_{L p}}{L_{p}}\right)^{2}
$$

and

$$
\frac{A_{c}}{A_{o}}=0.780 ; K_{C}=0.4 ; K_{e}=0.2,
$$

where $K_{C}, K_{e}$ - coefficients for pressure drop given by Kays W. M. and London A. L. [20].

Figure 7 presents results for pressure drop core, where the Multi-Louvered has significant influence. How expected, the pressure drop is higher for the relative right Reynold number, which characterizes the complex geometric of the radiator.

Results for Nusselt Number in turbulent flow at flat tube are presented in Figure 8 for three distinct correlations and Graphene Nanoribbon and Silicon Carbide. Dispersions occur between the correlations used, but the most significant occurs when comparing results for nanoparticles: Graphene Nanoribbon allows a significantly higher heat exchange than Silicon Carbide. In highlight, we have the average values obtained for the Nusselt number, concerning the three correlations represented through the above equations for the two types of nanoparticles considered in the analysis.

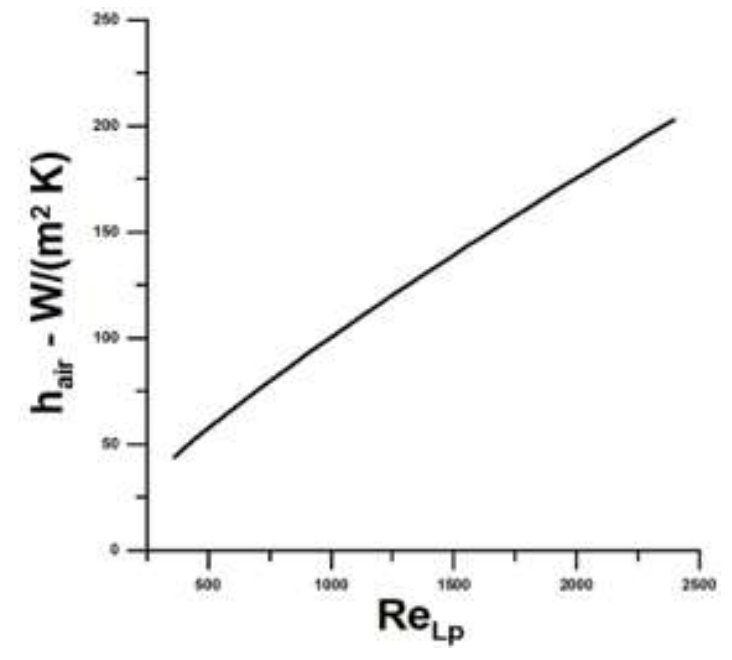

Figure 5 - Convection heat transfer coefficient in the heat exchanger core - Air

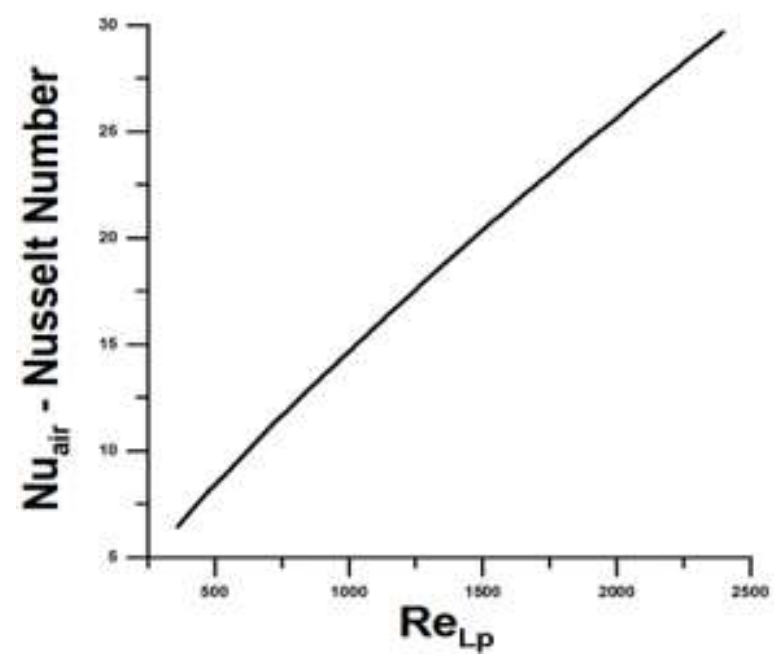

Figure 6 - Nusselt number in the heat exchanger core - Air

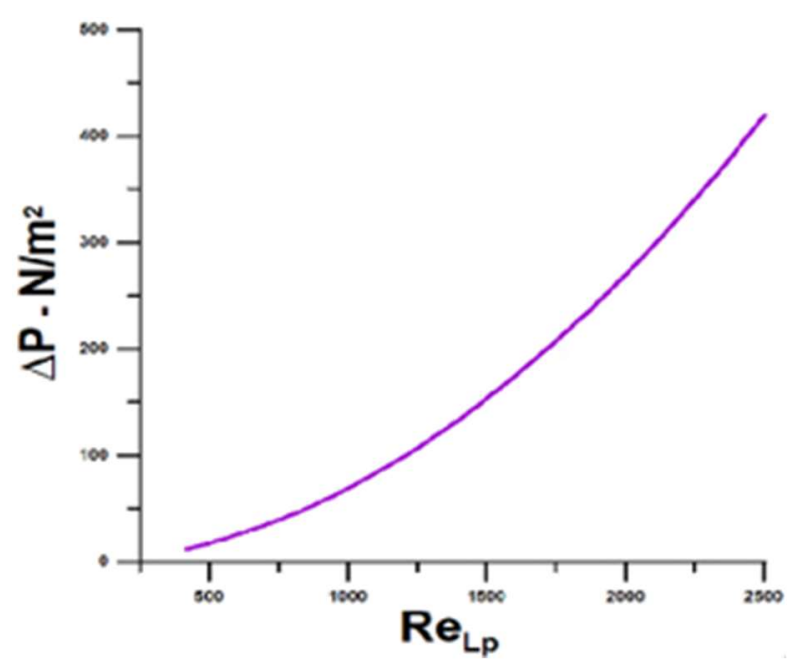

Figure 7 - Pressure Drop in the heat exchanger core - Air 


\subsection{Results for the coolant side}

Figure 8 presents the results of Nusselt number versus mass flow rate for volume fraction $\phi=0.05$ and EG $50 \%$ for Graphene Nanoribbon and Silicon Carbide.

The convection heat transfer coefficient, for turbulent flow, is obtained through the average Nusselt number for the two types of nanoparticles considered in the analysis: Graphene Nanoribbon and Silicon Carbide, with 0.05 for volume fraction (Figure 9). The value of the heat transfer coefficient obtained for Graphene Nanoribbon, for the volume fraction considered, is higher than twice the value obtained by Silicon Carbide. The values of thermal diffusivity can justify this result since Graphene Nanoribbon presents a value much higher than that of Silicon Carbide (Table 3).

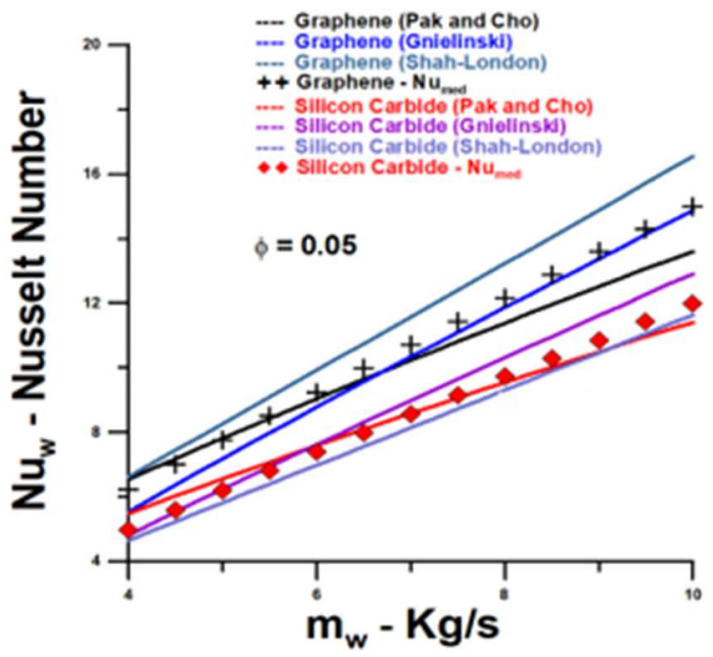

Figure 8 - Results of Nusselt number versus mass flow rate for volume fraction $\phi=0.05$ and EG $50 \%$ for Graphene Nanoribbon and Silicon Carbide

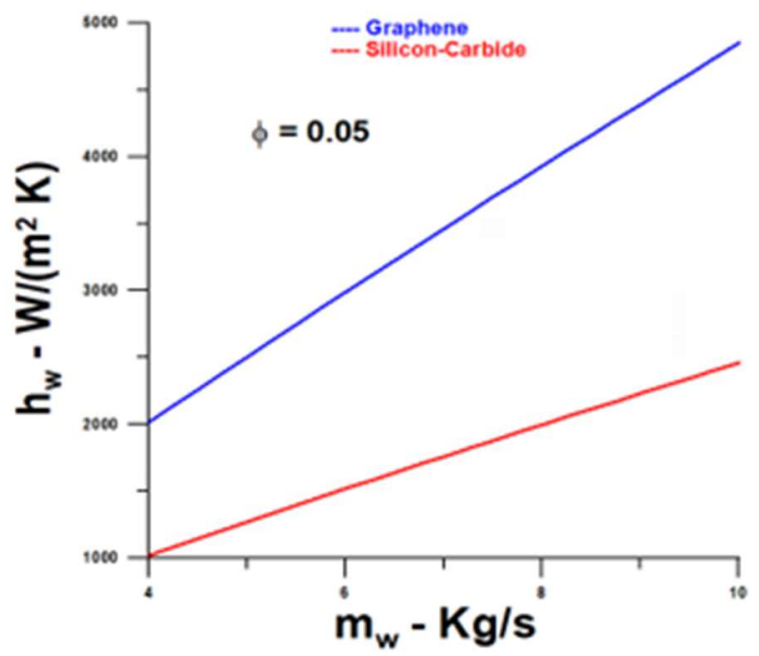

Figure 9 - Results of the coefficient of convection heat transfer versus mass flow rate for volume fraction $\phi=0.05$, EG $50 \%$ for Graphene Nanoribbon and Silicon Carbide

Figure 10 shows results for the heat transfer coefficient as a function of the volume fraction of Graphene
Nanoribbon particles, with mass flow rate as a parameter. Two correlations were used to obtain values for laminar flow, correlations presented by Nogueira [5], Shah, and London. For turbulent flow, a single correlation was used, the one obtained by Shah and London, for the three mass flow rates of the nanofluid.

It can be observed, through Figure 10, that the flow is laminar for fractions of relatively high nanoparticles, for the three mass flows considered. Relevant fact, in this analysis, is that the equation used by Shah and London, Laminar regime, is not sensitive to the change in the mass flow rate of the nanofluid.

The correlation obtained by Nogueira E. [19] demonstrates that the flow is laminar, for whatever the fraction value by volume of the Graphene nanoparticles when the mass flow of the nanofluid is relatively low, i.e., $1.0 \mathrm{~kg} / \mathrm{s}$. For higher flow rates, $5.0 \mathrm{~kg} / \mathrm{s}$, and $10.0 \mathrm{~kg} / \mathrm{s}$, the flow is laminar for relatively high fractions and have different values for the heat transfer coefficient. For turbulent flow and relatively low fractions of nanoparticles, the heat transfer coefficient is significantly high for mass flow rates of $5.0 \mathrm{~kg} / \mathrm{s}$ and $10.0 \mathrm{~kg} / \mathrm{s}$. These hight values for the heat transfer coefficient are a favorable result and of great practical importance, since lower values for the fraction in volume can reduce the costs of the compact heat exchanger (Radiator).

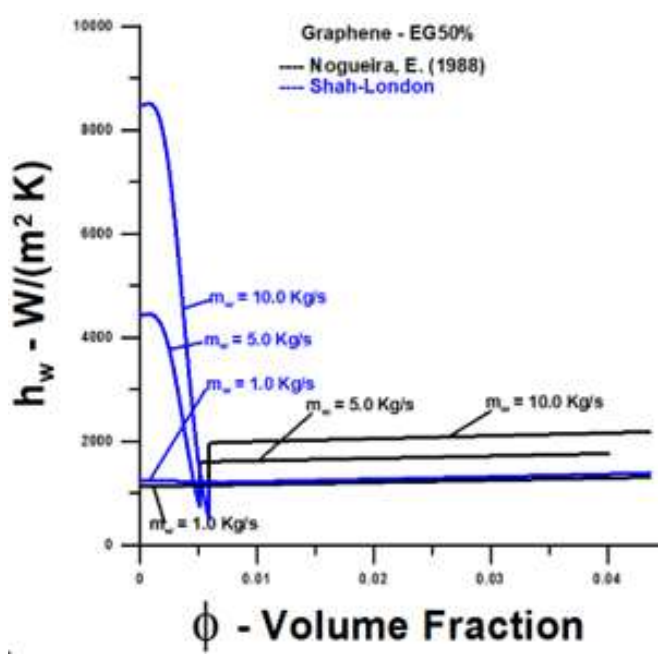

Figure 10 - Results of the coefficient of convection heat transfer versus volume fraction variation of Graphene Nanoribbon and $\mathrm{EG} 50 \%$

Figure 11 presents results similar to that of Figure 10. In this case, it should be considered that the Reynolds number influences both the flow rate and the volume fraction of nanoparticles. It can be concluded that the flow laminarization process for high fractions of nanoparticles occurs, as already observed by Nogueira E. [5].

Figure 11 presents a three-dimensional view for the variation of the convection heat transfer coefficient as a function of the volume fraction of the Graphene Nanoribbon nanoparticles and the Reynolds number. The influence of the volume fraction, and the mass flow rate, on the variation of the convection heat transfer coefficient 
and the Reynolds number, and the flow laminarization process for high volume fractions, can be observed more clearly.

Figure 12 presents a three-dimensional view for the variation of the Nusselt number as a function of the volume variation of the Graphene Nanoribbon nanoparticles and the Reynolds number. The conclusions, in qualitative terms, are similar to that of Figure 12: the influence of the volume fraction, and the mass flow rate, on the variation of the Nusselt number and the Reynolds number, and the flow laminarization process for high volume fractions, can be observed more clearly.

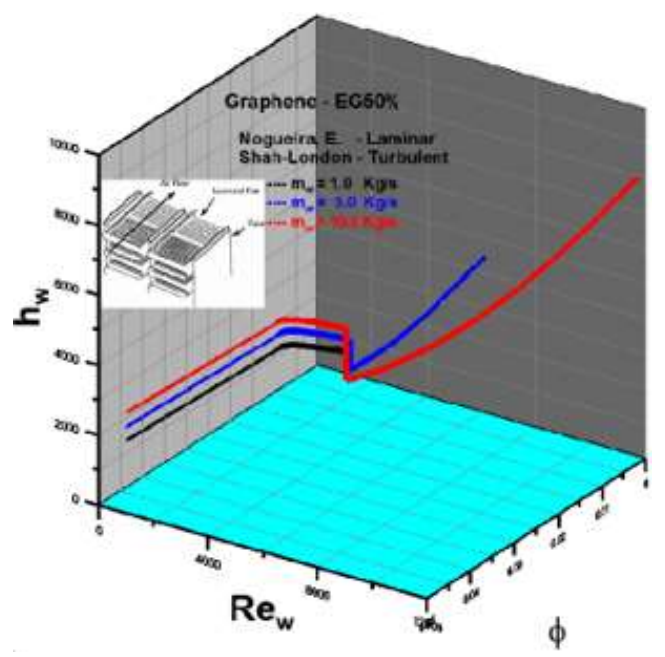

Figure 11 - Results of the coefficient of convection heat transfer versus volume fraction variation of Graphene Nanoribbon and Reynolds number

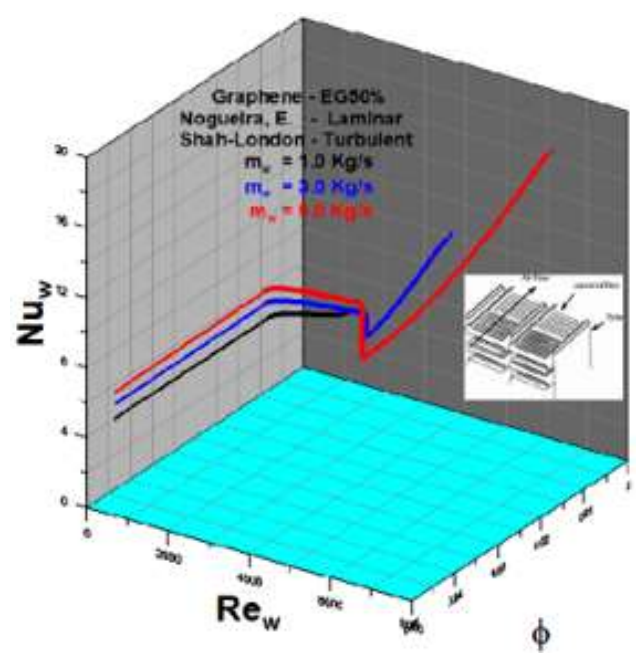

Figure 12 - Results of Nusselt number versus volume fraction variation of Graphene Nanoribbon and Reynolds number

The pressure drop, concerning the mass flow of the EG $50 \%$ nanofluid, for different values of the fraction by volume, is represented through Figure 13, for Graphene Nanoribbon and Silicon Carbide nanoparticles. It can be observed that the pressure drop for Graphene Nanoribbon, for the same fraction of nanoparticles, is slightly higher than the pressure drop associated with Silicon Carbide. As expected, since the pressure drop tends asymptotically to the pressure drop associated with Ethylene Glycol, the difference decreases to a lower value of the volume fraction.

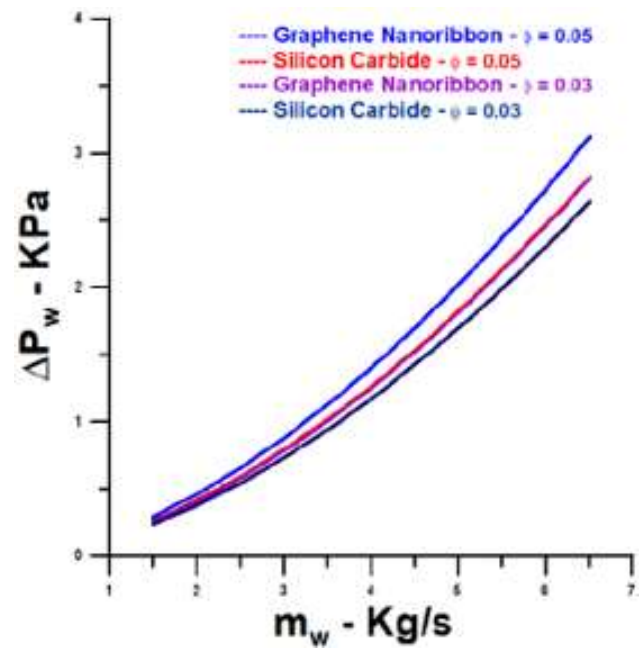

Figure 13 - Results for pressure drop versus mass flow rate of nanofluid, for the different volume fraction of Graphene Nanoribbon and Silicon Carbide

\section{Conclusions}

The flat tube of Multi-Louvered finned radiator is used for obtained results of thermal and hydraulic for the performance of nanofluids using Graphene Nanoribbon and Silicon Carbide in a Water-Ethylene Glycol as base fluid. The main conclusions reached in this work are as follows.

Graphene Nanoribbon allows a significantly higher heat exchange than Silicon Carbide. The value of the heat transfer coefficient obtained for Graphene Nanoribbon, for the volume fraction considered, is higher than twice the amount received by Silicon Carbide. The values of thermal diffusivity can justify the result above since Graphene Nanoribbon presents a value much higher than that of Silicon Carbide. The flow is laminar for fractions of relatively high nanoparticles, for both, Graphene Nanoribbon and Silicon Carbide. The flow is laminar, for whatever the fraction value by volume of the Graphene nanoparticles when the mass flow of the nanofluid is relatively low, i.e. $1.0 \mathrm{~kg} / \mathrm{s}$. For turbulent flow and relatively small fractions of nanoparticles, the heat transfer coefficient is significantly high for mass flow rates of 5.0 $\mathrm{kg} / \mathrm{s}$ and $10.0 \mathrm{~kg} / \mathrm{s}$ of Graphene Nanoribbon. These hight values for the heat transfer coefficient that mentioned above is a favorable result and of great practical importance, since lower values for the fraction in volume can reduce the costs of the compact heat exchanger (Radiator). The pressure drop for Graphene Nanoribbon, for the same fraction of nanoparticles, is slightly higher than the pressure drop associated with Silicon Carbide. 


\section{References}

1. Yadav, J. P., Singh, B. R. (2015). Study on performance evaluation of automotive radiator. S-JPSET, Vol. 2(2), pp. 47-56, doi: 10.18090/samriddhi.v2i2.1604.

2. Sivashanmugam, P. (2012). Application of Nanofluids in Heat Transfer. InTech Open, pp. 411-440, doi: 10.5772/52496.

3. Sivalingam, A.; Balusamy, T. (2018). Review on heat transfer enhancement using nanofluids in heat exchangers. International Journal of Science and Research, Vol. 7(2), pp. 1113-1116, doi: 10.21275/ART2018203.

4. Yerrennagoudaru, H., Manjunatha, K., Prasad, B. V., Sandeep, K., Kumar, S. V. (2020). Nano fluids for heat exchanger. International Journal of Engineering Science and Innovative Technology, Vol. 5(4), pp. 82-89.

5. Nogueira, E. (2019). Thermohydraulic performance in the flow of copper oxide (CuO) or aluminum oxide (A12O3) water-borne nanofluids in a finned flat tube heat exchanger (automotive radiator). IOSR Journal of Mechanical and Civil Engineering, Vol. 16(5), pp. 1-12, doi: 10.9790/1684-160540112.

6. Chen, J., Liu, B., Gao, X. (2020). Thermal properties of graphene-based polymer composite materials: A molecular dynamics study. Results in Physics, Vol. 16, 102974, doi: 10.1016/j.rinp.2020.102974.

7. Zadeh, S. J. M., Goharshadi, E. K. (2014). Thermal conductivity and heat transport properties of Graphene Nanoribbon. Journal of Nanoparticle Research, Vol. 16, 2553, doi: 10.1007/s11051-014-2553-5.

8. Gerhardt, R. (2011). Properties and Applications of Silicon Carbide. InTech Open, doi: 10.5772/615.

9. Abderrazak, H., Hmida, E. S. (2014). Silicon Carbide: Synthesis and Properties. InTech Open, pp. 361-388, doi: 10.5772/15736.

10. Alhusaiki-Alghamdi, H. M. (2019). Effect of silicon carbide ( $\mathrm{SiC}$ ) nanoparticles on the spectroscopic properties and performance of PMMA/PC polymer blend. Journal of Modern Physics, Vol. 10, pp. 487-499, doi: 10.4236/jmp.2019.105034.

11. Alipala, C. G., Paylaga, G. J., Paylaga, N. T., Bantaculo, R. V. (2015). Thermal conductivity of silicon-graphene nanoribbon (SIGNR): An equilibrium molecular dynamics (EMD) simulation. Advanced Materials Research, Vol. 1105, pp. 280-284, doi: 10.4028/www.scientific.net/AMR.1105.280.

12. Selvam, C., Lal, D. M., Harish, S. (2017). Enhanced heat transfer performance of an automobile radiator with graphene-based suspensions. Applied Thermal Engineering, Vol. 123, pp. 50-60, doi: 10.1016/j.applthermaleng.2017.05.076.

13. Dong, J., Chen, J., Chen, Z., Zhang, W., Zhou, Y. (2007). Heat transfer and pressure drop correlations for multi-louvered fin compact heat exchangers. Energy Conversion and Management, Vol. 48(5), pp. 1506-1515.

14. Sarkar, J., Tarodiya, R. (2013). Performance analysis of louvered fin tube automotive radiator using nanofluids as a coolant. Int. J. Nanomanufacturing, Vol. 9(1), pp. 51-65, doi: 10.1504/IJNM.2013.052881.

15. Maiga, S. E. B., Nguyen, C. T., Galanis, N., Roy, G. (2004). Heat transfer behaviors of nanofluids in a uniformly heated tube. Superlattices Microstructures, Vol. 35(3-6), pp. 543-547.

16. Pak, B. C., Cho, Y. I. (1998). Hydrodynamic and heat transfer study of dispersed fluids with submicron metallic oxide particles. Experimental Heat Transfer, Vol. 11(2), pp. 151-170, doi: 10.1016/j.icheatmasstransfer.2014.01.003.

17. Hussein, A. M., Bakar, R. A., Kadirgama, K., Sharma, K. V. (2014). Heat transfer enhancement using nanofluids in an automotive cooling system. International Communication in a Heat and Mass Transfer, Vol. 53, pp. 195-202.

18. Gnielinski, V. (1976). New equation for heat and mass transfer in turbulent pipe and channel flow. J Int. Chem Eng., Vol. 16, pp. 359-68.

19. Nogueira, E. (1988). Laminar flow and heat transfer in immiscible fluids without stratification. Technological Institute of Aeronautics.

20. Kays, W. M., London, A. L. (1984). Compact Heat Exchangers. MacGraw-Hill, New York. 